\title{
Will transcatheter valve-in-valve become the standard for replacing the degenerative aortic valve bioprosthesis? Hold your horses, the jury is still out
}

\author{
Jessica Forcillo, MD, MSc, FRCSC, Lillian L. Tsai, AB, and Vinod H. Thourani, MD
}

From the Division of Cardiothoracic Surgery, Emory University School of Medicine, Atlanta, Ga.

Disclosures: V.H.T. serves on an advisory board for St Jude Medical, Edwards Lifesciences, Boston Scientific, and Abbott Medical. V.H.T. performs research for Medtronic, Edwards Lifesciences, St Jude, Directflow, and Sorin Medical. All other authors have nothing additional to disclose with regard to commercial support.

Received for publication Aug 28, 2015; accepted for publication Aug 29, 2015; available ahead of print Sept 28, 2015 .

Address for reprints: Vinod H. Thourani, MD, Emory University Hospital Midtown, 550 Peachtree St, NE, 6th Floor, Medical Office Tower, Atlanta, GA 30308 (E-mail: vthoura@emory.edu).

J Thorac Cardiovasc Surg 2015;150:1568-9

$0022-5223 / \$ 36.00$

Copyright (c) 2015 by The American Association for Thoracic Surgery

http://dx.doi.org/10.1016/j.jtcvs.2015.08.114

Cardiac surgeons and cardiologists are confronted with an increasing number of elderly patients being seen with structural valve degeneration of previously placed surgical bioprosthetic heart valves. According to the US Department of Health and Human Services, by 2030 the elderly population will be about 72.1 million, more than twice the number in 2000. This represents a staggering proportion of the overall population of approximately $19 \%$. In this issue of The Journal of Thoracic and Cardiovascular Surgery, Conradi and colleagues ${ }^{1}$ report their cumulative experience of implanting 6 types of transcatheter heart valves in degenerated bioprostheses through different anatomic access sites. They found that valve-in-valve ( $\mathrm{ViV}$ ) placement can be performed safely and with acceptable hemodynamic and clinical outcomes in all 4 valve positions.

With the increasing trend of younger patients choosing bioprosthetic valves for their primary operation to minimize or eliminate the need for lifelong warfarin, the need to decide between surgical and transcatheter reoperative valve surgery is expected to increase during the next decade. In most series of surgical reoperative aortic valve surgery, the 30-day operative mortality ranges from $4 \%$ to $9 \%$. $^{2-4}$ A large series of patients younger than 60 years with a pericardial prosthesis implanted in the aortic position reported a freedom from structural valve degeneration of $57 \% \pm 6 \%$ at 15 years. ${ }^{5}$ Reoperation occurred approximately $11 \pm 5$ years after the initial aortic valve surgery. ${ }^{5}$ Conradi and colleagues ${ }^{1}$ reported an index procedure time to $\mathrm{ViV}$ of $9.3 \pm 4.9$ years. Among the high-risk patient population, Conradi and colleagues ${ }^{1}$ showed a 30 -day mortality of 5.6\% in the patients undergoing aortic ViV placement. A recent series of 3380 patients from the Society of Thoracic Surgeons database who underwent reoperative aortic valve replacement showed that the operative mortality is acceptable but higher than that of the first surgery $(4.6 \%$ vs $2.2 \%$ ). Reoperative aortic valve replacement was associated with a higher rate of major morbidities $(21.6 \%$ vs

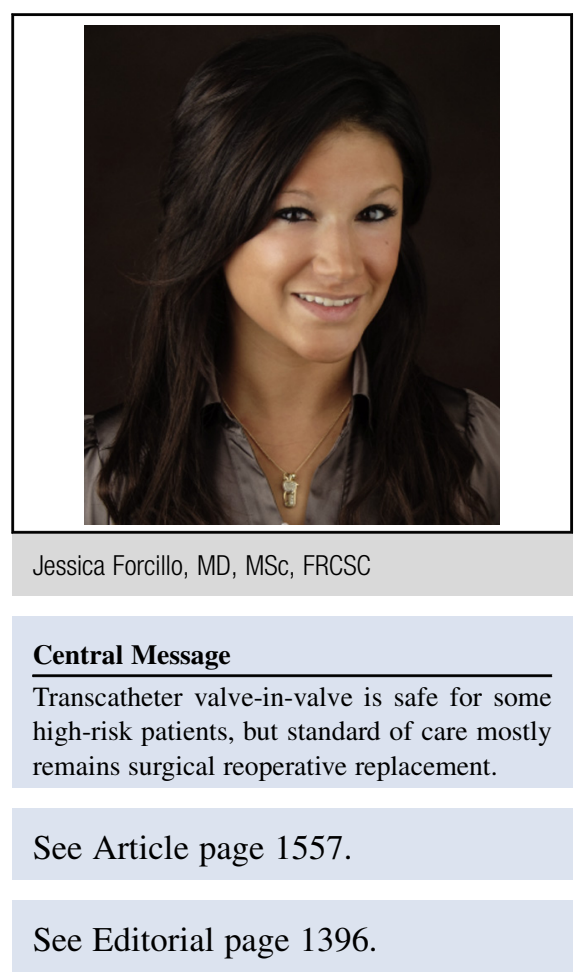

$11.8 \%$ ), including postoperative stroke, aortic insufficiency, pacemaker requirement, and vascular complications. These adverse events may be overcome by a less invasive technique such as $\mathrm{ViV}$ placement. ${ }^{6}$

Currently, it is not uncommon to recommend a bioprosthetic valve for primary operations in younger patients, with the possibility of a $\mathrm{ViV}$ transcatheter aortic valve replacement in the future. It is important to implant a valve size of at least $23 \mathrm{~mm}$ to avoid patient-prosthesis mismatch. Conradi and colleagues ${ }^{1}$ demonstrated that the mean aortic valve gradient obtained during ViV with a surgical 21-mm valve was significantly higher than with larger surgical valve sizes. Correspondingly, Dvir and associates ${ }^{7}$ showed that 1-year survival of patients who underwent a $\mathrm{ViV}$ procedure was lower among patients with small initial bioprosthesis ( $\leq 21 \mathrm{~mm}$; hazard ratio, 2.04). To accomplish the goal of an adequate initial surgical valve, it is vital to prevent patient-prosthesis mismatch by implanting an adequately sized valve through either root enlargement or stentless valve techniques.

There remains a steep learning curve for the performance of a transcatheter ViV placement. Whereas Conradi and 
colleagues ${ }^{1}$ noted that the transfemoral ViV placement was performed in only $43 \%$ of their patients, we expect that in the future most of these procedures will be performed through the femoral artery. Furthermore, the majority of these procedures have been performed in stented aortic valves. ${ }^{6}$ In patients who previously received stentless valves, valves without annular markers, or valves with high valvular struts, the implantation of a transcatheter valve has a higher rate of complications, including device migration, embolization, and coronary occlusion., ${ }^{8,9}$ Conradi and colleagues ${ }^{1}$ showed a high mortality ( $8 \%$ ), even when the procedures were performed in a relatively young patient population (mean age 74 years). A variety of prostheses were used in their study, however, leading to the potential of a learning curve for each device. With a small number of patients and at the beginning of an experience, focusing on 1 or 2 available prostheses might have resulted in more accurate and reliable results. Additionally, the high mortality may be explained by the fact that a majority of their procedures were performed through a transapical approach $(53 \%){ }^{6}$

The procedural success for ViV placement in the mitral, tricuspid, and pulmonary heart valves is encouraging. As noted in the series of Conradi and colleagues, ${ }^{1}$ however, there was an 8\% 30-day all-cause and cardiovascular cause mortality among all patients and a $17.6 \%$ mortality among those undergoing elective mitral $\mathrm{ViV}$ placement. There should be some caution against overzealous performance of this procedure, and continued monitoring of outcomes in other series is necessary.

As with every transformative technology, it remains imperative to evaluate the short- and long-term outcomes of a minimally invasive technique when compared with the criterion standard of open surgical techniques. The heart team must make these decisions in conjunction with the patient not only for the primary valve but also for the ViV procedure. For elderly, high-risk patients with structural valve degeneration, transcatheter options may provide improved short-term outcomes. The valve community eagerly awaits larger series with adjudicated outcomes of the transcatheter $\mathrm{ViV}$ procedure.

\section{References}

1. Conradi L, Silaschi M, Seiffert M, Lubos E, Blankenberg S, Reichenspurner H, et al. Transcatheter valve-in-valve therapy using six different devices in four anatomic positions: clinical outcomes and technical considerations. J Thorac Cardiovasc Surg. 2015;150:1557-67.e1-3.

2. Potter DD, Sundt TM III, Zehr KJ, Dearani JA, Daly RC, Mullany CJ, et al. Operative risk of reoperative aortic valve replacement. J Thorac Cardiovasc Surg. 2005; 129:94-103.

3. Davierwala PM, Borger MA, David TE, Rao V, Maganti M, Yau TM. Reoperation is not an independent predictor of mortality during aortic valve surgery. J Thorac Cardiovasc Surg. 2006;131:329-35.

4. Leontyev S, Borger MA, Davierwala P, Walther T, Lehmann S, Kempfert J, et al Redo aortic valve surgery: early and late outcomes. Ann Thorac Surg. 2011;91: 1120-6.

5. Forcillo J, El Hamamsy I, Stevens LM, Badrudin D, Pellerin M, Perrault LP, et al The Perimount valve in the aortic position: twenty-year experience with patients under 60 years old. Ann Thorac Surg. 2014;97:1526-32.

6. Kaneko T, Vassileva CM, Englum B, Kim S, Yammine M, Brennan M, et al Contemporary outcomes of repeat aortic valve replacement: a benchmark for transcatheter valve-in-valve procedure. Ann Thorac Surg. July 21, 2015 [Epub ahead of print].

7. Dvir D, Webb JG, Bleiziffer S, Pasic M, Waksman R, Kodali S, et al. Valve-inValve International Data Registry Investigators. Transcatheter aortic valve implantation in failed bioprosthetic surgical valves. JAMA. 2014;312:162-70.

8. Duncan A, Davies S, Di Mario C, Moat N. Valve-in-valve transcatheter aortic valve implantation for failing surgical aortic stentless bioprosthetic valves: A single-center experience. J Thorac Cardiovasc Surg. 2015;150:91-8.

9. Pasic M, Unbehaun A, Dreysse S, Buz S, Drews T, Kukucka M, et al. Transapical aortic valve implantation after previous aortic valve replacement: clinical proof of the "valve-in-valve" concept. J Thorac Cardiovasc Surg. 2011; 142:270-7. 